\title{
Successful Treatment of Cryoglobulinaemia with Rituximab
}

\author{
M. Choudhry N. Rao R. Juneja \\ Department of Renal Medicine, Flinders Medical Centre, Bedford Park, S.A., Australia
}

\section{Key Words}

Rituximab · Cryoglobulinaemia · Non-Hodgkin's lymphoma

\begin{abstract}
Cryoglobulinaemia is a systemic inflammatory condition characterised by immune complexmediated small-to-medium-sized vasculitis. It has a wide variety of presentations ranging from bruising, neuropathy, and hepatosplenomegaly to acute renal failure. Mixed cryoglobulinaemia is the most common type and is strongly associated with hepatitis C. Management approaches include use of cyclophosphamide, prednisolone, and plasmapheresis, with differing views on alternative treatments in resistant cases. Rituximab has emerged as an attractive option in resistant cases on account of its potent immunosuppressive effects on B cells. We describe a case of type 2 mixed cryoglobulinaemia in association with non-Hodgkin's lymphoma resistant to standard treatments which responded well to rituximab. This case is remarkable as mixed cryoglobulinaemia associated with non-Hodgkin's lymphoma presenting with nephritis is unusual, and, contrary to the high rate of recurrence in lymphoma-related cryoglobulinaemia, our patient has not shown any recurrence over 24 months. This highlights an alternative treatment modality which can be used in patients not responsive to existing managements for this condition with benefits of minimal side effects and no oncogenetic potential.
\end{abstract}

\section{Background}

Cryoglobulinaemia is a systemic inflammatory vasculitic disorder. It is classified into type 1 (monoclonal due to paraprotein disorders), type 2 (mixed polyclonal and monoclonal secondary to hepatitis $\mathrm{C}$ ), and type 3 (polyclonal due to lymphoproliferative disorders). The most common type described in the literature is secondary to hepatitis $\mathrm{C}$, with a prevalence described as high as $50 \%$ [1]. Renal disease in mixed cryoglobulinaemia is present in approximately $20 \%$ of patients at the time of diagnosis [2]. 
Clinical presentation encompasses a wide variety of features from generalised bruising, hepatosplenomegaly, and acute renal failure to peripheral neuropathy and hypocomplementaemia [3, 4]. Histological diagnosis can be obtained by skin or renal biopsy. Endocapillary proliferation, intraluminal thrombi, and thickening of the glomerular basement membrane are the most specific histological findings for type 2 cryoglobulinaemia [5].

Treatment options for cryoglobulinaemia are limited, and randomised controlled trials are reasonably lacking. The current mainstay of management includes plasmapheresis with high-dose prednisolone and cyclophosphamide and treatment of the underlying cause. Rituximab is a monoclonal anti-CD20 antibody used in the treatment of a variety of autoimmune diseases [6].

We describe a case of type 2 mixed cryoglobulinaemia associated with nonHodgkin's lymphoma successfully treated with rituximab.

\section{Case Report}

A 61-year-old female presented with severe community-acquired pneumonia complicated by acute renal failure. She had a background of type 2 diabetes mellitus and chronic obstructive airway disease. The renal failure was attributed to acute tubular necrosis secondary to sepsis and hypotension. At that time, the urine did not show any red cells or casts.

Her renal function initially remained stable and then worsened rapidly with significant fluid overload. She required 4 sessions of haemodialysis in the intensive care unit. Her renal function improved, and she became dialysis independent. The patient was discharged home after 45 days of hospital stay with normal renal function. She represented with acute pulmonary oedema and skin rash, requiring readmission to the intensive care unit within $48 \mathrm{~h}$ of discharge. Physical examination was consistent with pulmonary hypertension, splenomegaly, hepatomegaly, and bilateral pleural effusion. The skin lesions were typical of vasculitis and were distributed mainly in the extremities. Her positive investigations were: dysmorphic red cells in urine, proteinuria (24-hour urine protein $1 \mathrm{~g}$ ), hypoalbuminaemia (serum albumin $24 \mathrm{~g} / \mathrm{l}$ ), low complement levels, and positive serology for mixed cryoglobulinaemia.

Renal ultrasound showed normal sized kidneys and normal echotexture. Rheumatoid factor was weakly positive and HCV RNA was negative, as were all other autoimmune screens. Renal biopsy revealed diffuse mesangiocapillary glomerulonephritis accompanied by hyaline capillary thrombi with focal mild endarteritis affecting the intimal zone of one small artery consistent with cryoglobulinaemic vasculitis (fig. 1, fig. 2 ).

The patient was treated with 5 sessions of plasma exchange and 2 sessions of haemodialysis over 1 week, followed by prednisolone and cyclophosphamide. There was a good initial response with a decrease in cryoglobulin levels within 3 weeks and symptomatic improvement. Cyclophosphamide had to be discontinued because of thrombocytopenia. The patient was discharged on prednisolone $50 \mathrm{mg}$ daily, and her renal function was normal on discharge. However, she became symptomatic again on prednisolone after 2 weeks, with reappearance of rash. Her serum cryoglobulins became positive/high and complements were low. She had worsening proteinuria and significant weight gain secondary to fluid retention. The patient's urea level was disproportionately high (with steroids and diuretics on board) compared to her creatinine level. She required 5 sessions of plasmapheresis and was recommenced on reduced cyclophosphamide with a dose of $50 \mathrm{mg} / 100$ alternate days. She was discharged from hospital again with normal renal function. Serum cryoglobulin was negative at this stage.

After 12 days, she represented with fluid overload and pneumonia. Cyclophosphamide was ceased due to recurrent thrombocytopenia, sepsis, and herpes zoster of the chest wall on the left side. She was commenced on intermittent haemodialysis (for better control of uraemia and fluid retention) and 
plasmapheresis on alternate days for 1 month. Haematology opinion was sought in view of new-onset paraproteinaemia ( $3 \mathrm{~g} / \mathrm{l})$ with monoclonal IgM kappa (85 mg/l), but negative Bence Jones protein in urine, normal skeletal survey, and no light chains in the serum. Her bone marrow biopsy showed a low-grade lymphoma with predominant CD20 expression on B cells.

As the patient was not showing any clinical improvement and was requiring regular dialysis/ultrafiltration, second-line treatment was discussed. She was given $600 \mathrm{mg}$ rituximab/week for 3 weeks in addition to prednisolone and responded within 1 week, with dramatic improvements in symptoms, absence of cryoglobulins, and normal complement levels. In view of her multiple prior infections (pneumonia, herpes zoster, and urosepsis), it was decided to administer only 3 doses of rituximab.

The patient was discharged home on prednisolone and ongoing intermittent haemodialysis. Her renal function gradually improved, and she became dialysis independent after 7 months, with complete renal recovery. Cryoglobulin titres have remained negative and serum complements normal over the current follow-up of 24 months. She continues to be on prednisolone $5 \mathrm{mg}$ daily. There have been no side effects including infections on follow-up.

\section{Discussion}

Non-Hodgkin's lymphoma-associated cryoglobulinaemia presenting with acute renal failure is uncommon. To our knowledge, this is the first case report of a patient with mixed cryoglobulinaemia associated with non-Hodgkin's lymphoma who presented with nephritis and acute renal failure [7, 8].

Treatment options for cryoglobulinaemia comprise of plasmapheresis, cyclophosphamide, and steroids. Our patient was responsive to prednisolone, plasmapheresis, and cyclophosphamide but had a recurrence which was resistant to cytotoxics, steroids, and plasma exchange.

Rituximab has been shown to be useful in essential and secondary cryoglobulinaemia [7, 9]. It is a human-mouse chimeric monoclonal antibody that reacts with CD20 antigen, a transmembrane protein present in different maturation steps of B lymphocytes (from early pre-B to mature lymphocyte), thus directly and selectively targeting B cells and suppressing the production of rheumatoid factor [7, 10]. Rituximab has proved effective and very well tolerated in B-cell non-Hodgkin's lymphomas $[7,11,12]$, but there are conflicting case reports as well $[13,14]$.

Rituximab has the advantage of allowing avoidance of serious immunosuppression and side effects $[7,11]$ and it lacks direct oncogenetic properties that could favour the progression of indolent lymphomas into an aggressive lymphoma. Although a complete and long-term remission of lymphoma is obtained in a minority of cases after rituximab monotherapy [11], this case is unique for the fact that our patient has not shown signs of clinical or serological recurrence for 24 months after treatment with rituximab. She has not required maintenance therapy, although concerns about rituximab not being curative and need for ongoing rituximab maintenance therapy have been raised [15] The patient showed complete recovery with regard to renal function, although acute renal failure on presentation in mixed cryoglobulinaemia implies poor prognosis [16].

The usual regimen consists of $375 \mathrm{mg} / \mathrm{m}^{2}$ with 1 dose per week for 4 weeks. The incidence of side effects is variable $[2,17]$. Our patient received 3 doses of rituximab. The fourth dose was not given because of pancytopenia secondary to cytotoxics and sepsis predating the use of rituximab. 


\section{Urology}

Our case report highlights the ongoing necessity for further exploration of new therapeutic agents in the treatment of resistant cryoglobulinaemia associated with lymphoma. No study has yet examined the efficacy of rituximab in mixed cryoglobulinaemia in a prospective controlled manner. The low number of patients in individual centres would make randomised controlled trials impossible. The current literature is restricted to case reports and case series, and further prospective study is needed to fully determine the role of rituximab.

Resistant cryoglobulinaemia is a life-threatening condition, and the optimal management is unknown at this moment. Rituximab has emerged as a well-tolerated and effective treatment with no long-term oncogenetic potential, which was confirmed by this case report.

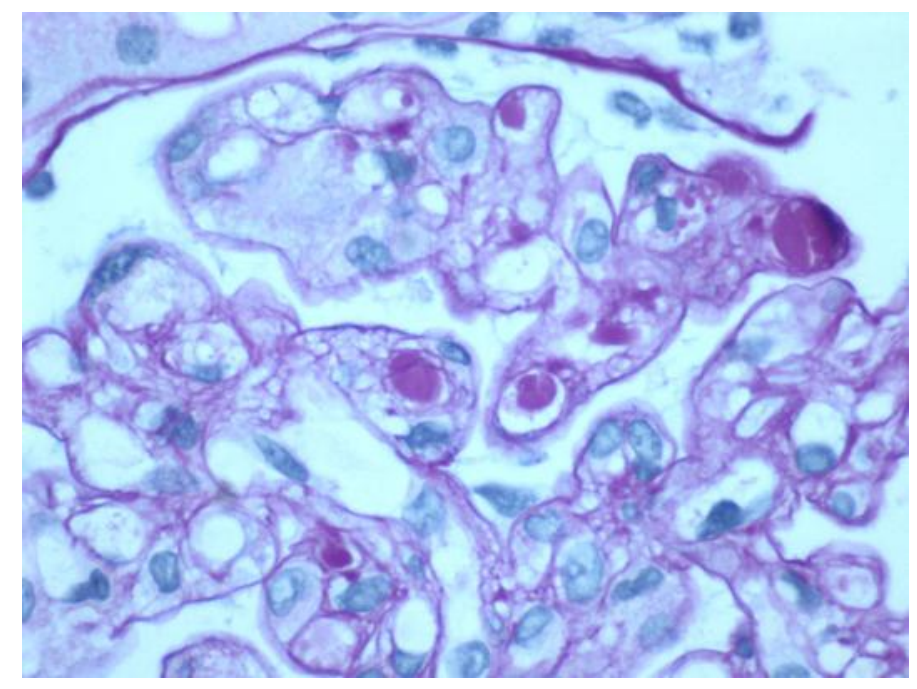

Fig. 1. Intraluminal microthrombi. 


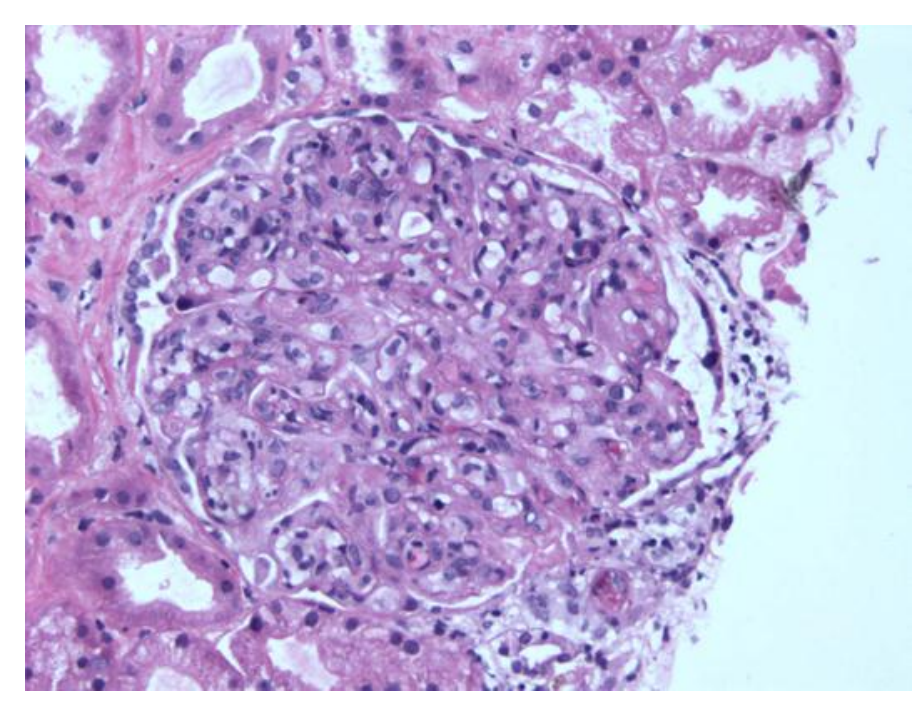

Fig. 2. Mesangiocapillary glomerulonephritis.

\section{References}

1 Cicardi M, Cesana B, Del Ninno E: Prevalence and risk factors for the presence of serum cryoglobulins in patients with chronic hepatitis C. J Viral Hepat 2000;7:138-143.

2 Monti G, Galli M, Invernizzi F, Pioltelli P, Saccardo F, Monteverde A, Pietrogrande M, Renoldi P, Bombardieri S, Bordin G, et al: Cryoglobulinaemias: a multi-centre study of the early clinical and laboratory manifestations of primary and secondary disease. GISC. Italian Group for the Study of Cryoglobulinaemias. QJM 1995;88:115-126.

3 Matignon M, Cacoub P, Colombat M, et al: Clinical and morphologic spectrum of renal involvement in patients with mixed cryoglobulinemia without evidence of hepatitis $\mathrm{C}$ virus infection. Medicine (Baltimore) 2009;88:341-348.

4 Kishore D, Misra S: Cryoglobulinemia presenting as acute polyneuropathy. J Assoc Physicians India 2008;56:998-999.

5 Sinico RA, Winearls CG, Sabadini E, Fornasieri A, Castiglione A, D’Amico G: Identification of glomerular immune deposits in cryoglobulinemia glomerulonephritis. Kidney Int 1988;34:109-116.

6 Ramos-Casals M, García-Hernández FJ, de Ramón E, et al: Off-label use of rituximab in 196 patients with severe, refractory systemic autoimmune diseases. Clin Exp Rheumatol 2010;28:468-476.

$>7$ Zaja F, De Vita S, Mazzaro C, Sacco S, Damiani D, De Marchi G, Michelutti A, Baccarani M, Fanin R, Ferraccioli G: Efficacy and safety of rituximab in type II mixed cryoglobulinemia. Blood 2003;101:38273834.

8 Foessel L, Besancenot JF, Blaison G, Magy-Bertrand N, Jaussaud R, Etienne Y, Maurier F, Audia S, Martin T: Clinical spectrum, treatment, and outcome of patients with type II mixed cryoglobulinemia without evidence of hepatitis C infection. J Rheumatol 2011;38:716-722.

$>9$ Roccatello D, Baldovino S, Rossi D, et al: Rituximab as a therapeutic tool in severe mixed cryoglobulinemia. Clin Rev Allergy Immunol 2008;34:111-117.

10 Reff ME, Carner K, Chambers KS, Chinn PC, Leonard JE, Raab R, Newman RA, Hanna N, Anderson DR: Depletion of B cells in vivo by a chimeric mouse human monoclonal antibody to CD20. Blood 1994;83:435-445.

11 Maloney DG, Grillo-López AJ, White CA, Bodkin D, Schilder RJ, Neidhart JA, Janakiraman N, Foon KA, Liles TM, Dallaire BK, Wey K, Royston I, Davis T, Levy R: IDEC-C2B8 (Rituximab) anti-CD20 monoclonal antibody therapy in patients with relapsed low-grade non-Hodgkin's lymphoma. Blood 1997;90:21882195. 
12 Pfreundschuh M, Kuhnt E, Trümper L, Osterborg A, Trneny M, Shepherd L, Gill DS, Walewski J, Pettengell R, Jaeger U, Zinzani PL, Shpilberg O, Kvaloy S, de Nully Brown P, Stahel R, Milpied N, López-Guillermo A, Poeschel V, Grass S, Loeffler M, Murawski N; MabThera International Trial (MInT) Group: CHOP-like chemotherapy with or without rituximab in young patients with good-prognosis diffuse large-B-cell lymphoma: 6-year results of an open-label randomised study of the MabThera International Trial (MInT) Group. Lancet Oncol 2011;12:1013-1022.

13 Bryce AH, Dispenzieri A, Kyle RA, et al: Response to rituximab in patients with type II cryoglobulinemia. Clin Lymphoma Myeloma 2006;7:140-144.

14 Baronciani D, Angelucci E, Gaziev J, Visani G: Inefficacy of rituximab in a case of low grade non-Hodgkin's lymphoma with cryoglobulinemia. Haematologica 2002;87:ELT33.

15 Terrier B, Launay D, Kaplanski G, et al: Safety and efficacy of rituximab in nonviral cryoglobulinemia vasculitis: Data from the French Autoimmunity and Rituximab registry. Arthritis Care Res 2010;62:1787-1795.

16 Tarantino A, Campise M, Banfi G, et al: Long-term predictors of survival in essential mixed cryoglobulinemic glomerulonephritis. Kidney Int 1995;47:618-623.

17 Sailler L: Rituximab off label use for difficult-to-treat auto-immune diseases: reappraisal of benefits and risks. Clin Rev Allergy Immunol 2008;34:103-110. 